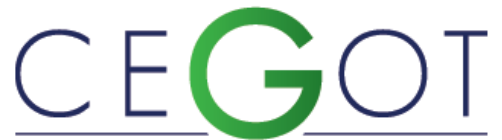

Centro de Estudos de Geografia e Ordenamento do Território

Geografia e Ordenamento do Território, Revista Eletrónica Centro de Estudos de Geografia e Ordenamento do Território http://cegot.org

Pimenta, LiAnNe

Programa de Pós-Graduação em Ciências Ambientais da Universidade do Estado do Pará (UEPA)

Travessa Padre Eutíquio 2279, 66.025-230, Belém, Pará, Brasil lianneborja@yahoo.com.br

\title{
Beltrão, NoRMA
}

Programa de Pós-Graduação em Ciências Ambientais da Universidade do Estado do Pará (UEPA)

66.095-015, Belém, Pará, Brasil

normaelybeltrao@gmail.com

\section{Gemaque, Amanda}

Programa de Pós-Graduação em Ciências Ambientais da Universidade Federal do Pará (UFPA)

67.015-410, Ananindeua, Pará, Brasil

amanda.gemaque@yahoo.com.br

\section{Pontes, Altem}

Programa de Pós-Graduação em Ciências Ambientais da Universidade do Estado do Pará (UEPA)

66.095-100, Belém, Pará, Brasil

altempontes@hotmail.com

\section{Dinâmica do uso e cobertura da terra em municípios prioritários: uma análise no município de Moju, Pará no período de 2008 a 2014}

Dynamics of use and land cover in priority municipalities: An Analysis in the municipality of Moju, Pará in the period 2008 to 2014

Referência: Pimenta, Lianne et al. (2018). Dinâmica do uso e cobertura da terra em municípios prioritários: uma análise no município de Moju, Pará no período de 2008 a 2014. Revista de Geografia e Ordenamento do Território (GOT), n. ${ }^{\text {o } 14}$ (setembro). Centro de Estudos de Geografia e Ordenamento do Território, p. 267-281, dx.doi.org/10.17127/got/2018.14.011

\section{RESUMO}

O Município de Moju, localizado no Estado do Pará, tem sofrido modificações na sua paisagem natural por meio da expansão de atividades produtivas como a agricultura e pecuária, fato que contribuiu para sua entrada na lista de municípios prioritários do Ministério do Meio Ambiente, em 2011. Assim, este estudo teve como objetivo analisar a dinâmica da mudança do uso e cobertura da terra no município de Moju-PA, no período de 2008-2014. Mapeando as principais classes de uso e cobertura da terra por meio de imagens de satélite oriundas do Programa de Monitoramento da Floresta Amazônica Brasileira por Satélite (PRODES). Os dados apontaram um aumento de aproximadamente $22 \%$ das áreas destinadas às pastagens e redução de $4 \%$ de áreas de floresta. Entretanto, houve a manutenção de cerca de $40 \%$ de áreas de floresta e redução das taxas de desmantamento no período analisado.

Palavras-chave: uso e cobertura da terra, Prodes, TerraClass, desmatamento, Amazônia. 


\section{ABSTRACT}

The Municipality of Moju, located in the State of Pará, has undergone changes in its natural landscape through the expansion of productive activities such as agriculture and livestock, a fact that contributed to its inclusion in the list of priority municipalities of the Ministry of Environment in 2011. This study aimed to analyze the dynamics of land use change and land cover in the municipality of Moju-PA, in the period 2008-2014. Mapping the main classes of land use and coverage through satellite images from the Brazilian Amazon Forest Satellite Monitoring Program (PRODES). The data indicated an increase of approximately $22 \%$ of the areas destined to the pastures and reduction of $4 \%$ of forest areas. However, there was maintenance of about $40 \%$ of forest areas and reduction of deforestation rates in the analyzed period.

Keywords : land use and coverage, Prodes, TerraClass, deforestation, Amazon.

\section{Introdução}

O estudo da dinâmica das paisagens, bem como das estruturas que as integram, tem potencial para fornecer informações técnicas capazes de apoiar a elaboração e a implementação de políticas públicas, pois capturam o modo como a sociedade se relaciona com a terra e suas consequências socioeconômicas e ambientais (CARDOSO et al., 2016). Para a obtenção de informações sobre uso e ocupação da terra, é necessário conhecer e entender os aspectos e impactos que se originam das atividades antrópicas sobre o meio ambiente (CÔRTES e D'ANTONA, 2014).

Nessa perspectiva, as técnicas de geoprocessamento representam um conjunto de tecnologias que englobam coleta, processamento e a análise dos dados, que resultam na apresentação de um referencial geográfico que permite, entre outros objetivos, a análise da dinâmica no uso e cobertura da terra (MARTINS e RODRIGUES, 2012).

Como importante fator no acompanhamento do uso da terra, tem-se o mapeamento, que subsidia a avaliação, o planejamento e o controle voltados ao uso sustentável dos recursos naturais (ALMEIDA e VIEIRA, 2014). O mapeamento, feito através de geoprocessamento, é um instrumento de análise e monitoramento da mudança da cobertura e do uso da terra capaz de acompanhar tais processos, e que tem sido muito utilizado tanto pela comunidade científica quanto por tomadores de decisão governamental em vários setores, que interagem com os critérios de sustentabilidade (CASTELO e ALMEIDA, 2015). 
No tocante à conversão florestal em pastagens ou em áreas agrícolas, entre outros usos, causa preocupação as causas e consequências dessa dinâmica, especialmente na Amazônia que sofre pressões antrópicas que vão desde a expansão agropecuária até a urbanização sem planejamento, levando à perda de biodiversidade e de serviços ecossistêmicos, os quais têm potencial para atuar como fatores intensificadores das alterações climáticas (IDESP, 2014).

Para Fearnside (2006) o desenvolvimento dessa região, somado ao aumento das atividades produtivas contribuíram para o agravamento do desmatamento. Com o objetivo atender demandas externas, a partir de um modelo exógeno, fatores como avanço da pecuária na fronteira agrícola, conflitos de terras entre fazendeiros, posseiros e povos indígenas, além do aumento populacional contribuíram efetivamente com esse processo.

Desta forma, as políticas de integração nacional criaram condições legais, financeiras e infraestruturais para os grandes eventos, a partir dos grandes projetos hidroelétricos, minerais, madeireiros e agropecuários que reinventam a região como fronteira de recursos, espaço vazio com potencial de atração para investidores (NAHUM, 2011).

Na Amazônia Paraense, o Município de Moju, localizado na porção Nordeste do Estado, tem sofrido ao longo dos anos grandes pressões decorrentes da expansão de suas atividades produtivas, gerando altas taxas de desmatamento, os quais conduziram o município para a lista de municípios prioritários do Ministério do Meio Ambiente - MMA. Segundo o MMA (2016) os critérios adotados para a inclusão de municípios na lista de prioritários são: "Área total de floresta desmatada no município; área total de floresta desmatada nos últimos três anos; e, por fim, o aumento da taxa de desmatamento em pelo menos três, dos últimos cinco".

De acordo com esses critérios, e segundo a Portaria no 175/2011 o município de Moju passou a integrar a lista de prioritários de 2011, tornando-o foco de ações fiscalizatórias e de maior rigor na aplicabilidade das leis vigentes, em ações promovidas pelo IBAMA. Além disso, com o embargo, aumentaram as exigências quanto ao licenciamento e georreferenciamento de unidades e domicílios rurais, para a obtenção de concessão de créditos aos proprietários das terras; além de, também, serem recusadas, por grandes 
empreendimentos frigoríficos, carnes oriundas de áreas embargadas (ASSUNÇÃO e ROCHA, 2014; BRASIL, 2011).

Neste contexto, é fundamental compreender as tendências da dinâmica do uso e cobertura da terra diante das principais pressões atuantes e suas implicações, fornecendo subsídios para o planejamento de ações capazes de mitigar os impactos decorrentes de práticas econômicas historicamente consolidadas e de novos empreendimentos. Assim, o estudo tem como objetivo caracterizar a mudança do uso e cobertura da terra no município de Moju-PA, no período de 2008-2014, mapeando as principais classes de uso e cobertura da terra por meio de dados espaciais fornecidos por ações governamentais de monitoramento do desmatamento na Amazônia como o Programa de Monitoramento da Floresta Amazônica Brasileira por Satélite (PRODES) e o projeto Terra Class.

Além desta introdução, apresentando uma visão geral do tema abordado, referencial teórico, relevância da pesquisa e os objetivos, este artigo foi dividido em mais três seções. A segunda seção aborda a metodologia empregada, com apresentação da área de estudo, procedimentos de coleta e análise dos dados. Em seguida, na terceira seção, foram apresentados e discutidos os resultados obtidos a respeito da dinâmica do uso e cobertura da terra no município de Moju e, ao final, na quarta seção, as considerações finais com base nas alterações que foram observadas no território estudado.

\subsection{O Projeto Terra Class}

Com o intuito de combater o avanço e as consequências que o desmatamento ocasionava na Amazônia Legal, foi delineado pelo Ministério do Meio Ambiente o Programa de Monitoramento da Floresta Amazônica Brasileira por Satélite (PRODES), através do Instituto Nacional de Pesquisas Espaciais (INPE). Assim, para atender a esta demanda, desenvolveuse o projeto TerraClass, o qual teve por objetivo capturar imagens orbitais de áreas que já haviam sido desflorestadas permitindo a elaboração de um mapa que descrevesse em 2008, e nos anos subsequentes (2010, 2012 e 2014) o patamar em que se encontrava o uso e a cobertura da terra no período analisado pelo projeto (EMBRAPA e INPE, 2012).

Os dados fornecidos pelo projeto tem possibilitado a identificação de tendências para mudança e uso da terra, os quais subsidiam a elaboração de políticas públicas e a tomada de 
decisão das diferentes esferas (federal, estadual e municipal) no combate ao desmatamento. $\mathrm{O}$ Projeto TerraClass utiliza dados gerados através da análise de imagens em órbitas-ponto pelo satélite Landsat Thematic Mapper (TM) 5 - Landsat/TM5, com resolução espacial de 30m, com projeção no Sistema Lat/Long (UTM) e com Datum SAD/69, que encontram-se disponíveis para consulta e download no Portal do INPE (INPE-CRA, 2016; EMBRAPA e INPE, 2012).

Segundo os sumários disponíveis do Projeto TerraClass (2008/2014) as classes utilizadas para análise da mudança são Agricultura anual, Mosaico de ocupações, Área urbana, Mineração, Pasto limpo, Pasto sujo, Regeneração com pasto, Pasto com solo exposto, Vegetação secundária, Área não observada e Outros (áreas com coberturas diferenciadas, exemplo: bancos de areias, etc.). Dessas, apenas seis classes serão utilizadas neste estudo, as quais encontram-se elencadas na tabela 1 a seguir.

\begin{tabular}{|c|c|}
\hline Classes & Definição \\
\hline Agricultura Anual & $\begin{array}{l}\text { Áreas com predomínio de culturas de ciclo } \\
\text { anual, com emprego de tecnologia, insumos, } \\
\text { defensivos e mecanização, entre outros. }\end{array}$ \\
\hline Pasto Limpo & $\begin{array}{l}\text { Áreas de pastagem em processo produtivo com } \\
\text { predomínio de vegetação herbácea, e cobertura } \\
\text { de gramíneas. }\end{array}$ \\
\hline Pasto Sujo & $\begin{array}{l}\text { Áreas de pastagem em processo produtivo com } \\
\text { predomínio da vegetação herbácea e cobertura } \\
\text { de gramíneas associadas à presença de } \\
\text { vegetação arbustiva esparsa. }\end{array}$ \\
\hline $\begin{array}{l}\text { Área } \\
\text { observada }\end{array}$ & $\begin{array}{l}\text { Áreas com interpretação impossibilitada pela } \\
\text { presença de nuvens ou sombra de nuvens, no } \\
\text { momento de passagem do satélite, além das } \\
\text { áreas recentemente queimadas. }\end{array}$ \\
\hline Desflorestamento & $\begin{array}{l}\text { Corresponde a supressão total da vegetação } \\
\text { nativa de determinada área para o uso } \\
\text { alternativo do solo. }\end{array}$ \\
\hline Floresta & $\begin{array}{l}\text { Vegetação que apresente predominância de } \\
\text { indivíduos lenhosos, onde as copas das árvores } \\
\text { se tocam formando um dossel. }\end{array}$ \\
\hline
\end{tabular}

Tabela 1 - Classes de uso da terra e suas definições Fonte: EMBRAPA e INPE(2012); IBAMA(2016); SNIF(2016). 


\section{Materiais e métodos}

\section{1. Área de estudo}

O município de Moju está localizado no Nordeste do Estado do Pará, possuindo uma área de $9.094,10 \mathrm{~km}^{2} \mathrm{e}$, segundo estimativa do IBGE (2015), conta com uma população de 77.385 habitantes. De acordo com a classificação de Köppen, o clima do município é Ami (quente e úmido), com temperatura média anual na faixa de 25,5 으. A umidade relativa do ar se aproxima de $85 \%$ e, tem os meses de janeiro a junho sua época de maior pluviosidade, contando com precipitação pluviométrica de 2.000 a 3.000 mm/ano (MODESTO JÚNIOR et al., 2008). A economia do município baseia-se no cultivo de culturas como a mandioca, o açaí e o dendê, além da extração de madeira, produção de carvão e pecuária (IBGE; 2015).

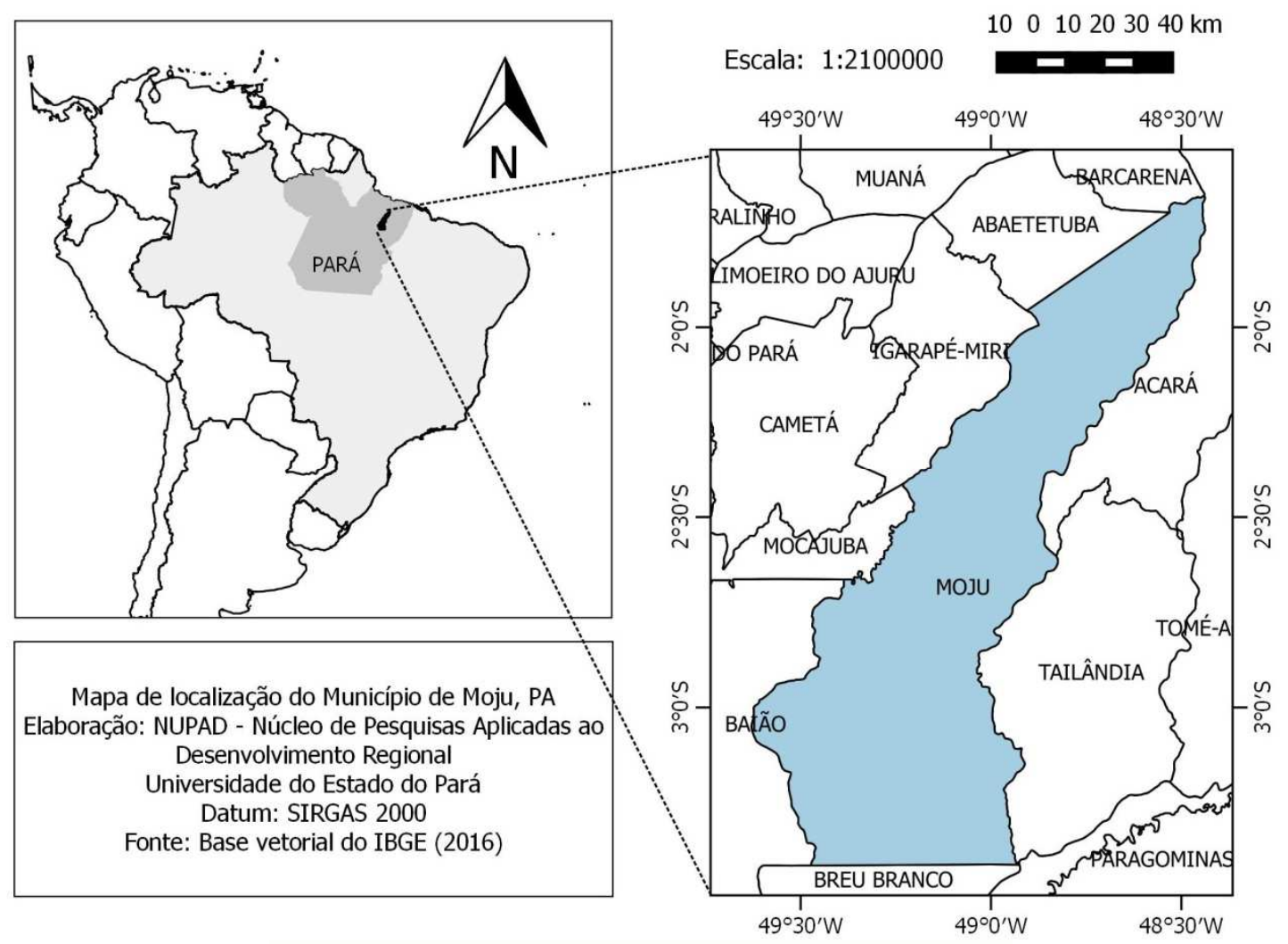

Figura 1 - Mapa de Localização do município de Moju.

Fonte: Autores, (2016).

\subsection{Coleta e análise de dados}

Para o desenvolvimento deste estudo, foram utilizadas as fontes de dados do IBGE (Instituto Brasileiro de Geografia e Estatística); MMA (Ministério do Meio Ambiente); INPE (Instituto Nacional de Pesquisas Espaciais) e PRODES (Programa de Monitoramento da Floresta 
Amazônica Brasileira por Satélite, para obter os dados de desmatamento de 2005 a 2014; INCRA (Instituto Nacional da Colonização e Reforma Agrária), para o número de assentamentos de reforma agrária localizado na área de estudo; e no Portal do Programa Municípios Verdes, além de boletins e artigos científicos pertinentes ao assunto abordado.

Para a análise espacial foi utilizado o software livre "QGIS" (versão 2.8), que através de técnicas de geoprocessamento localizou espacialmente as principais classes de uso e cobertura da terra, a partir da base digital fornecida pelos projetos TerraClass e PRODES do INPE. Para subsidiar a análise da mudança no período selecionado, foram escolhidas seis (06) das onze classes mapeadas pelo TerraClass. Na classe "Pastagem", para fins de análise produtiva, foram considerados apenas as classes "Pasto Limpo" e "Pasto Sujo". Apesar de terem sido utilizados conceitos e dados do Projeto TerraClass, neste trabalho o termo "Desflorestamento" será substituído por "Desmatamento", por se tratar do termo mais frequentemente encontrado nas publicações acadêmicas.

Para análise da dinâmica da mudança de classes de uso da terra entre os anos de 2008 e 2014, foi elaborada uma matriz de transição com base na metodologia apresentada por Adami et al. (2015) que também utilizou os dados do projeto TerraClass. Assim, a partir dos qualitativos de cada classe e ano selecionados, foi possível mapear a dinâmica da permanência e conversão no período em análise.

\section{Resultados e discussão}

\subsection{Mudança do uso da terra no município de Moju}

O município de Moju encontra-se na lista de municípios Prioritários do MMA desde 2011. Segundo o portal do Programa Municípios Verdes (PMV) (2016), Moju é considerado "embargado", pois ainda não atendeu à todas as metas estabelecidas no Termo de Ajustamento de Conduta (TAC) firmado entre a Prefeitura do Município e o Ministério Público Federal no mesmo ano, como o não atendimento de $80 \%$ de unidades rurais cadastradas no CAR. O município ainda detém significativas taxas de desmatamento na 
Amazônia, apesar de que os desmatamentos mapeados entre 2013 e 2014 tenham sido menores que $40 \mathrm{~km}^{2}$ (PRODES, 2016).

A partir dos dados fornecidos pelo Projeto TerraClass para os anos de 2008, 2010, 2012 e 2014, foi possível mapear as principais classes de uso da terra no município de Moju, reduzindo as 11 (onze) classes originais do projeto para apenas 6 (seis) conforme apresentadas na tabela 2 .

\begin{tabular}{l|l|l|l|l}
\hline Classes & $\mathbf{2 0 0 8}$ & $\mathbf{2 0 1 0}$ & $\mathbf{2 0 1 2}$ & $\mathbf{2 0 1 4}$ \\
\hline Agricultura anual & $1,6 \%$ & $2 \%$ & $1,3 \%$ & $1,1 \%$ \\
\hline Pastagem (Limpo+Sujo) & $11,4 \%$ & $8,5 \%$ & $14,6 \%$ & $14,6 \%$ \\
\hline Floresta & $54 \%$ & $51,9 \%$ & $51 \%$ & $50 \%$ \\
\hline Desmatamento & $0,8 \%$ & $1,2 \%$ & $0,5 \%$ & $0,2 \%$ \\
\hline Área não observada & $1,4 \%$ & $3,8 \%$ & $0,8 \%$ & $3,1 \%$ \\
\hline Outros & $30,5 \%$ & $32,3 \%$ & $31,6 \%$ & $30,4 \%$ \\
\hline
\end{tabular}

Tabela 2 - Áreas relativas às classes de uso e cobertura da terra (em porcentagem) no município de Moju no período de 2008 e 2014.

Fonte: INPE-TerraClass, 2016.

As classes Agricultura anual, Pastagem, Floresta e Desmatamento, foram selecionadas por serem representativas dos principais usos da terra no Município e, portanto, indispensável à análise de suas dinâmicas ao longo do período analisado (2008 a 2014). As duas últimas classes foram especificadas e quantificadas de acordo com os dados fornecidos pelo TerraClass.

A classe "Área não observada" diz respeito às limitações encontradas no projeto TerraClass geralmente devido a disponibilidade de imagem de satélite ou a presença de nuvens que impedem o correto mapeamento das áreas no ano analisado. Esses quantitativos de áreas são importantes, pois poderiam ser alocadas para qualquer classe, mas naquele ano não foi possível sua identificação. Portanto, um maior ou menor quantitativo por classe pode não representar totalmente a realidade pois não houve $100 \%$ de mapeamento devido as áreas não observadas.

A classe "Outros" reuniu as demais classes existentes no TerraClass, mas que não foram selecionadas para análise no município de Moju. Percebe-se a partir dos quantitativos apresentados na Tabela 2, que houve significativas mudanças especialmente na classe "Floresta", que foi reduzida em cerca de $4 \%$ no período analisado. Outras classes também 
sofreram diminuição de área no município, tais como "Agricultura Anual" e "Desmatamento", com $0,5 \%$ e $1 \%$ de redução, respectivamente.

As áreas de pastagens tiveram um aumento e se estabilizaram nos dois últimos anos de análise (2012 e 2014), mantendo-se por volta de 14,6\% do território do município. A agricultura anual variou ano a ano mostrando uma tendência de redução, o que pode ter realmente ocorrido devido a expansão das áreas de pastagens destinadas a pecuária.

Com relação ao desmatamento ocorrido no município de Moju, dados do PRODES/INPE constatam a tendência de redução das taxas anuais especialmente após 2010, corroborando com os quantitativos encontrados com o mapeamento da classe "Desmatamento" a partir dos dados do TerraClass entre 2008 e 2014. A Tabela 3 a seguir apresenta os dados anuais de desmatamento no período de 2000 a 2014.

\begin{tabular}{l|l|l}
\hline Período & \multicolumn{1}{|c|}{$\begin{array}{c}\text { Desmatamento } \\
\text { acumulado } \\
\text { (km2 e \%) }\end{array}$} & \multicolumn{1}{|c}{$\begin{array}{c}\text { Incremento } \\
\text { (km2 e \%) }\end{array}$} \\
\hline 2000 & $2.688,0(29.44 \%)$ & N/A (0.00\%) \\
\hline 2001 & $3.257,5(35.68 \%)$ & $569,5(6.24 \%)$ \\
\hline 2002 & $3.332,4(36.50 \%)$ & $74,9(0.82 \%)$ \\
\hline 2003 & $3.449,8(37.79 \%)$ & $117,4(1.29 \%)$ \\
\hline 2005 & $3.578,8(39.20 \%)$ & $129,0(1.41 \%)$ \\
\hline 2006 & $3.659,2(40.08 \%)$ & $80,5(0.88 \%)$ \\
\hline 2009 & $3.768,7(41.28 \%)$ & $109,5(1.20 \%)$ \\
\hline 2010 & $3.848,0(42.15 \%)$ & $79,3(0.87 \%)$ \\
\hline 2011 & $3.964,2(43.42 \%)$ & $116,2(1.27 \%)$ \\
\hline 2012 & $4.031,5(44.16 \%)$ & $67,3(0.74 \%)$ \\
\hline 2014 & $4.147,4(45.43 \%)$ & $115,9(1.27 \%)$ \\
\hline
\end{tabular}

Tabela 3 - Série Temporal para o Desmatamento no município de Moju de 2000 a 2014. Fonte: Adaptado do PRODES-Digital (2016).

Como demonstrado na Tabela 3, em 2005 a perda florestal já chegava a 40,08\% do município, totalizando uma área de $3.659,2 \mathrm{~km}^{2}$. Em 2014, essa área já representava 47,04\% do município, ou seja, 4.293,9 $\mathrm{km}^{2}$. No entanto, como citado anteriormente, a partir de 2010 as taxas anuais de desmatamento ficaram abaixo de 1\%, o que pode ser explicado pelo 
conjunto de políticas públicas de combate ao desmatamento, além de outros incentivos, como o Programa Municípios Verdes e o Cadastro Ambiental Rural (CAR).

O município de Moju é composto por imóveis rurais na forma de propriedades rurais e posses que já cobrem uma área de $6.237,75 \mathrm{~km}^{2}$ cadastrados no Cadastro Ambiental Rural (CAR), equivalendo, esse valor a 69.71\% do total cadastrável $\left(8.947,97 \mathrm{~km}^{2}\right)(P M V, 2016)$. As informações geradas através do CAR são inseridas no Sistema Nacional de Cadastro Ambiental Rural (Sicar) contribuem para o desenvolvimento de políticas e projetos que visem ao controle, monitoramento, ao planejamento de estratégias para combater o desmatamento (MMA, 2014). Ressalta-se que quando ocorreu a publicação do Novo Código Florestal em 2012, o município já constava da lista de Municípios Prioritários do MMA, levando-o a firmar o Termo de Ajustamento de Conduta (TAC) com o Ministério Público em relação ao Programa Municípios Verdes, o que pode ter influenciado para a ligeira redução.

As classes de uso da terra selecionadas neste estudo e quantificadas por meio dos dados espaciais fornecidos pelo projeto TerraClass podem ser visualizadas na Figura 02, que representa o município de Moju nos anos de 2008, 2010, 2012 e 2014.

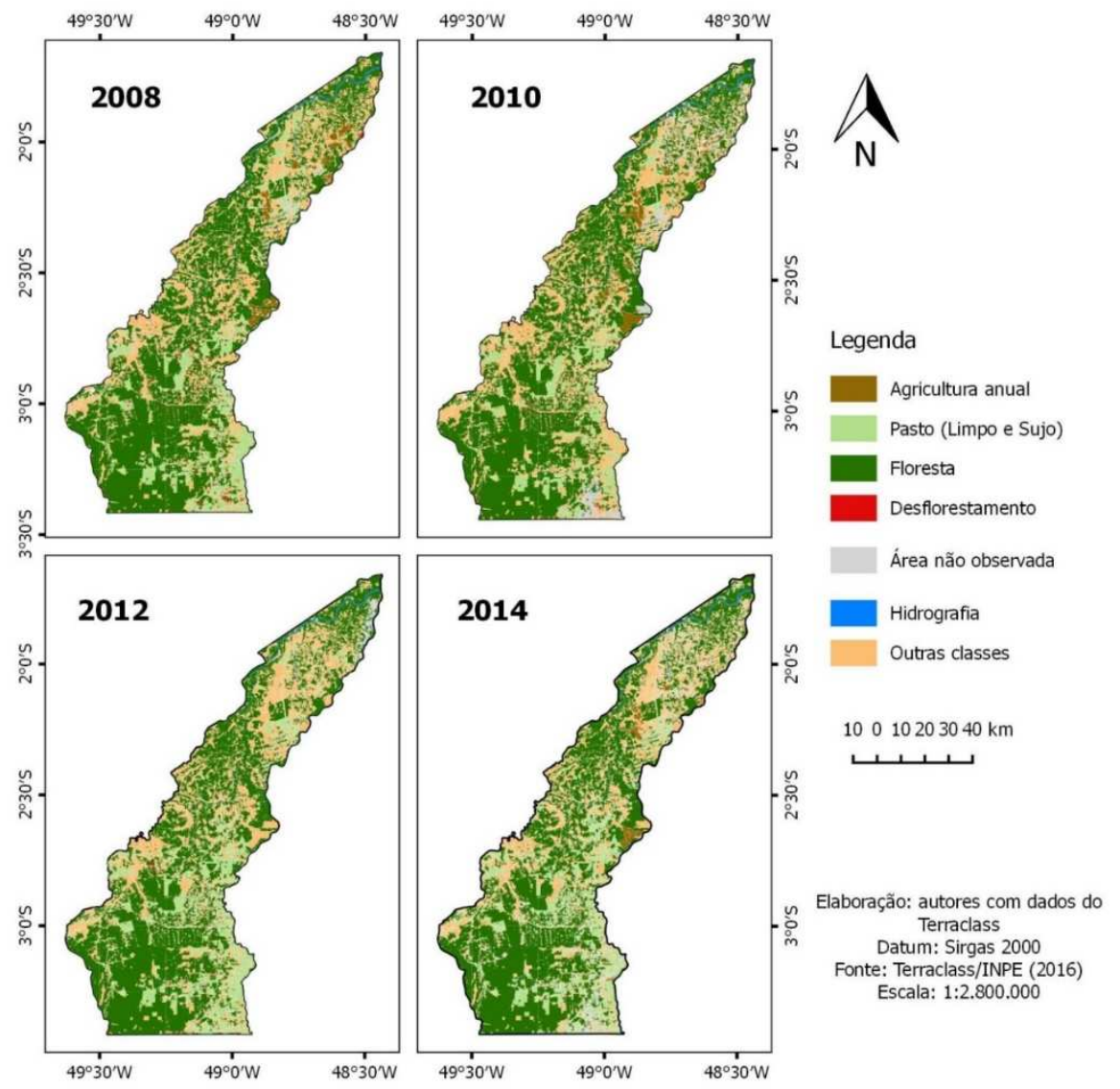

Figura 2 - Classificação e uso da terra em Moju nos anos de 2008 a 2014. Fonte: Elaborado com dados do Prodes (INPE, 2016). 
Nestes mapas destacam-se as seguintes informações: (i) as ocorrências de desmatamento são muito esparsas e pontuais, quase imperceptíveis quando plotadas junto a outras classes que possuem quantitativo de áreas bem maiores. Com isso, não está claro se as áreas desflorestadas estão associadas com a pequena produção agrícola existente ou a expansão de pastagem. (ii) pode-se perceber uma pequena redução de áreas de florestas comparando-se os mapas de 2008 e 2014, especialmente na região norte do município. (iii) áreas de pastagens, são identificadas mais claramente no ano de 2014, especialmente na região sudeste do município, na fronteira com o município de Tailândia. Também se percebe uma leve substituição de áreas que eram florestas em 2008 por pastagens em 2014, na região central do município.

Mediante o exposto e para melhor compreensão da dinâmica entre as classes analisadas durante o período em estudo, foi construída uma matriz de transição, a partir dos quantitativos gerados pelos dados espaciais de cada classe/ano, segundo a metodologia usada por Adami et al (2015). Assim, a matriz de transição apresentada na Tabela 4, corresponde às alterações ocorridas no município de Moju, no período 2008-2014, agregados de acordo com as classes selecionadas neste estudo.

\begin{tabular}{|c|c|c|c|c|c|c|c|}
\hline \multirow{2}{*}{\multicolumn{2}{|c|}{ Classes }} & \multicolumn{5}{|c|}{2014} & \multirow[b]{2}{*}{ Total } \\
\hline & & Agricultura & Pastagem & & Desma- & Outras & \\
\hline \multirow{6}{*}{$\stackrel{\infty}{\circ}$} & $\begin{array}{l}\text { Agricultura } \\
\text { anual }\end{array}$ & 60,00 & 4,97 & 0,07 & 0,00 & 86,95 & 151,99 \\
\hline & $\begin{array}{l}\text { Pastagem } \\
\text { (Limpo+Sujo) }\end{array}$ & 20,51 & 683,09 & 0,36 & 0,00 & 337,38 & $1.041,34$ \\
\hline & Floresta & 0,37 & 121,37 & $3.634,35$ & 18,16 & $1.137,86$ & $4.912,11$ \\
\hline & Desmatamento & 0,08 & 40,42 & 0,19 & 0,30 & 34,72 & 75,71 \\
\hline & Outras classes & 32,50 & 480,21 & 941,69 & 3,51 & $1.456,41$ & $2.914,32$ \\
\hline & Total & 113,46 & $1.330,06$ & $4.576,66$ & 21,97 & $3.053,32$ & $9.095,47$ \\
\hline
\end{tabular}

Tabela 4 - Matriz de transição entre as classes de uso da terra analisadas (em $\mathrm{km}^{2}$ ) entre os anos 2008 e 2014, município de Moju (PA).

Fonte: Adaptado EMBRAPA e INPE (2008-2014); INPE (2016). 
A composição de cada classe no ano de 2014 foi realizada a partir da identificação espacial da classe detectada pelo Projeto TerraClass em 2008. Como exemplo tem-se que, das áreas caracterizadas como Agricultura Anual em $2014\left(113,46\right.$ km²) $^{2}, 60$ km² já eram utilizadas para Agricultura Anual em 2008, mas 20,51 km² eram Pastagens (Limpo+Sujo), 0,37 km² foram convertidos de áreas de florestas, $0,08 \mathrm{~km}^{2}$ eram áreas desflorestadas e $32,50 \mathrm{~km}^{2}$ pertenciam a outras classes não identificadas no estudo.

Outros aspectos podem ser destacados: do total de 1.330,06 $\mathrm{km}^{2}$ de áreas identificadas como Pastagens em 2014, 683,09 km² (65,5\%) já eram pastagens em 2008, indicando a continuidade da atividade. Isto pode ter ocorrido devido a forte presença da pecuária na economia local. Segundo Cardoso et. al (2016), a pecuária pode ser considerada o principal agente causador do desmatamento municipal, haja vista que a área desmatada ocupada por pastos é muito superior as áreas ocupadas por agricultura anual.

Com o aumento das restrições para o desmatamento, foram utilizadas áreas de pastagens para atividade agrícola, percebido nos 20,51 $\mathrm{km}^{2}$ de pastagem em 2008 que foram convertidos para classe Agricultura Anual em 2014. 1,3\% de área de floresta foram convertidos em pastagem no período estudado, devendo-se provavelmente a forte vocação da região pela atividade pecuária, com o aumento do número de cabeças nos efetivos dos rebanhos, atendendo assim à necessidade de mais área.

Com relação à classe Floresta, a análise dos dados espaciais permitiu confirmar que os $3.634,35 \mathrm{~km}^{2}$ (40\%) de áreas que eram florestas em 2008, permaneceram em 2014. Porém, quando se compara o total de áreas em 2008 e 2014, percebe-se uma redução de 4\% das áreas florestadas. Apesar da diminuição das taxas de desmatamento, ainda foi observada uma considerável perda florestal nesse período.

Pela própria definição da classe "desflorestamento" no TerraClass, este só é registrado quando ocorre sobre vegetação nativa (floresta) não sendo aplicável na conversão das classes Agricultura anual e Pastagem, e por essa razão não houve desmatamento detectado nessas áreas no ano de 2014.

Por fim, é necessário ressaltar que "Outras classes" compreendem áreas não observadas, ou seja, áreas cuja presença de nuvens pode dificultar o adequado mapeamento de floresta, desmatamento e sua real área. 


\section{Considerações finais}

O município de Moju encontra-se desde 2011 na lista dos municípios prioritários do Ministério do Meio Ambiente. Em todas as esferas governamentais - federal, estadual e municipal - esforços têm sido direcionados para reduzir as taxas de desmatamento do município e retirá-lo da lista. Neste contexto, este estudo pretendeu caracterizar a mudança do uso e cobertura da terra no município no período 2008 a 2014, buscando dessa forma compreender as tendências diante das principais forçantes atuando no município, a fim de contribuir no planejamento de ações mais efetivas para reduzir as taxas de desmatamento e seus impactos.

Como resultados, foi possível atestar a redução das taxas de desmatamento, especialmente após o ano de 2010. No entanto, somente a partir de 2013 que houve o registro de áreas desmatadas anualmente menores que $40 \mathrm{~km}^{2}$. Através das análises espaciais foi possível caracterizar as ocorrências de desmatamento como esparsas e pontuais, podendo estar associadas tanto à expansão da agricultura familiar ou das pastagens já existentes. Com relação à dinâmica entre as classes, os dados apontaram um aumento de aproximadamente $22 \%$ das áreas destinadas às pastagens, evidenciando a manutenção da atividade pecuária na região.

É possível ainda verificar que dadas as restrições das atividades de desmatamento, há uma tendência de utilizar tanto para pastagem como para a agricultura anual, áreas que já foram alteradas, conforme os resultados apontados pela matriz de transição entre os anos de 2008 e 2014. Foi possível observar uma perda florestal significativa no município, entretanto os dados apontaram a diminuição no ritmo do desmatamento no período analisado.

Enquanto ferramenta de análise, as técnicas de geoprocessamento aplicadas aos bancos de dados espaciais disponibilizados pelos projetos PRODES e TerraClass do INPE, foram satisfatórias na elucidação da dinâmica do uso e cobertura da terra em Moju. Espera-se que futuros trabalhos possam contribuir com dados adicionais de atividades econômicas, crescimento urbano e dinâmica social, localizando-os espacialmente no município a fim de associá-los com as mudanças do uso da terra caracterizados e quantificados neste estudo. 


\section{Referências bibliográficas}

ADAMI M, GOMES AR, COUTINHO AC, ESQUERDO JCDM, VENTURIERI A. Dinâmica do uso e cobertura da terra no estado do Pará entre os anos de 2008 a 2012. (in) Anais XVII Simpósio Brasileiro de Sensoriamento Remoto - SBSR, João Pessoa-PB, Brasil, 25 a 29 de abril de 2015, INPE. Disponível: http://www.ppgca.ufpa.br/arquivos/repositorio/TEXTODOWN/.

ALMEIDA, A. S.; VIEIRA, I. C. G. Conflitos no uso da terra em áreas de preservação permanente em um polo de produção de biodiesel no estado do Pará. Revista Ambiente e Água. vol. 9 n. 3 Taubaté - Jul. / Sep 2014. Doi: http://dx.doi.org/10.4136/ambi-agua.1410.

ASSUNÇÃO, J.; ROCHA, R. Municípios Prioritários: Reputação ou Fiscalização?. Climate Policy Initiative CPI. 2014.

BRASIL. Ministério do Meio Ambiente. Dispõe sobre a lista de municípios situados no Bioma Amazônia onde incidem ações prioritárias de prevenção, monitoramento e controle do desmatamento ilegal. Portaria no 175, de 24 de maio de 2011.

BRASIL. Ministério do Meio Ambiente. Decreto no 7.830 de 17 de outubro de 2012. Dispõe sobre o Sistema de Cadastro Ambiental Rural, o Cadastro Ambiental Rural, estabelece normas de caráter geral aos Programas de Regularização Ambiental, de que trata a Lei no 12.651, de 25 de maio de 2012, e dá outras providências. DOU de 18/10/2012 (Seção 1, pág. 5).

CARDOSO, A. S.; TOLEDO, P. M.; VIEIRA, I. C. G. Barômetro Da Sustentabilidade Aplicado ao Município de Moju, Estado do Pará. Revista Brasileira de Gestão e Desenvolvimento Regional. V. 12, n. 1, p. 234-263, jan-abr/2016, Taubaté, SP, Brasil. 2016.

CASTELO, T. B.; ALMEIDA, O. T. Desmatamento e uso da terra no Pará. Revista de Política Agrícola. Ano XXIV No 991 - Jan./Fev./Mar. 2015. 2015.

CÔRTES, J. C. D'ANTONA, A. O. Dinâmicas no uso e cobertura da terra: Perspectivas e desafios da Demografia. Revista Brasileira de Estudos de População. Rio de Janeiro, v. 31, n.1, p. 191-210, jan./jun. 2014. 2014. Doi: http://dx.doi.org/10.1590/S0102-30982014000100011.

EMBRAPA e INPE. Empresa Brasileira de Pesquisa Agropecuária e Instituto Nacional de Pesquisas Espaciais. TerraClass. Levantamento de informações de uso e cobertura da terra na Amazônia. Sumário Executivo. 2012.

EMBRAPA e INPE. Empresa Brasileira de Pesquisa Agropecuária e Instituto Nacional de Pesquisas Espaciais. TerraClass. Levantamento de informações de uso e cobertura da terra na Amazônia. Sumário Executivo. 2014.

FEARNSIDE, P. M. Desmatamento na Amazônia: dinâmica, impactos e controle. Revista Acta Amazonica. VOL. 36(3) 2006: 395 - 400. 2006. Doi: http://dx.doi.org/10.1590/S0044-59672006000300018.

IBGE. Instituto Brasileiro de Geografia e Estatística. Censo Demográfico. 2015.

IDESP. Instituto de Desenvolvimento Econômico, Social e Ambiental do Pará. Estatística Municipal: Moju. 2014.

INPE. Instituto Nacional de Pesquisas Espaciais. Monitoramento da cobertura florestal da Amazônia por satélites - Sistema PRODES-Digital. 2016.

MARTINS, T. I. S.; RODRIGUES, S. C. Análise e mapeamento dos graus de fragilidade ambiental da bacia do médio - baixo curso do rio Araguari, Minas Gerais. Caderno de Geografia, v.22, n.38, 2012.

MODESTO JUNIOR, M. S.; ANDRADE, A. C. S.; ALVES, R. N. B. Transferência de tecnologia pelo método treino e visita para agricultura familiar no Município de Moju, Estado do Pará. In: Congresso da Associação Brasileira das Instituições de Pesquisa Tecnológica, 2008, Campina Grande. Os desníveis regionais e a inovação no Brasil: os desafios para as instituições de pesquisa tecnológica: resumos. Brasília, DF. 2008.

MMA. MINISTÉRIO DO MEIO AMBIENTE. Municípios Prioritários na Amazônia. 2016.

NAHUM, J.S. Região, discurso e representação: a Amazônia nos Planos de Desenvolvimento. Boletim de Geografia. Maringá, v. 29, n. 2, p. 17-31, 2011. 2011. Doi:10.4025/bolgeogr.v29i2.11001.

PMV. Programa Municípios Verdes. Ficha Resumo Município - Moju. 2016. 
SNIF. Sistema Nacional de Informações Florestais. Tipologias Florestais. 2016.

SOUZA, S. R.; MELLO, L. F. Análise do uso e ocupação do solo em um trecho da zona norte do município de São José dos Campos - SP. Caderno de Geografia, v.22, n.37, 2012. 2012. 